\title{
INVESTIGATION OF THE ELASTIC MODULUS OF POLYMER SLEEPERS UNDER A QUASISTATIC AND CYCLIC LOADING
}

\author{
Vít LOJDA ${ }^{1,{ }^{*}}$, Aran van BELKOM ${ }^{2}$, Hana KREJČIŘÍKOVÁ ${ }^{1}$ \\ ${ }^{1}$ Department of Railway Structures, Faculty of Civil Engineering, Czech Technical University in \\ Prague, Thakurova 7, Prague, Czech Republic. \\ ${ }^{2}$ Railway Engineering section, Engineering Structures Department, Faculty of Civil Engineering and \\ Geosciences, Technical University in Delft, Stevinweg 1, Delft, Netherlands. \\ corresponding author: vit.lojda@fsv.cvut.cz.
}

\section{Abstract}

In ballasted track, the wheel load is transmitted to the subgrade via sleepers commonly made of impregnated wood, prestressed concrete, steel or recently developed polymer sleepers. Mentioned material types of sleepers are characterized by different elastic moduli being a key parameter in any numerical model. Hence, this paper aims to determine the elastic modulus of sleepers subjected to a laboratory four-point bending test. Traffic resembling load level of $60 \mathrm{kN}$ adopted from a typical axle load distributed by the rails to the sleeper was applied in a quasistatic and cyclic loading. The samples included sleepers made of polymers complemented with wood and pre-stressed concrete. The results of this paper are based on the elastic modulus investigation. Main conclusions are focused on the sleeper's elastic modulus under changing loading frequencies. Wood and prestressed concrete sleepers indicated mainly elastic behaviour resulting in a constant elastic modulus. However, polymer sleepers showed a loading frequency dependent elastic modulus as a result of their viscous elastic behaviour. Moreover, the conclusions of this paper involve E-modulus measurements of impregnated beech sleepers in order to describe their piece by piece elasticity variation due to their natural origin.
\end{abstract}

\section{Keywords:}

Polymer sleeper; Bending experiment; Elastic modulus; Viscoelasticity; Cyclic loading.

\section{Introduction}

Railway sleepers are an essential part of the railway infrastructure. Their main function is to support the rails and distribute the wheel loads to the ballast [1]. In order to perform this load distributing function effectively, the bending stiffness of the sleeper is an essential parameter [2].

The stiffness of the railway track is important for track performance. Low track stiffness is correlated to high rail deflections which can induce fatigue in the rail. High track stiffness can lead to impact loads and vibrations. As described by Belkom [3], the sleeper bending stiffness plays a part in the determination of the track stiffness and should, therefore, lie within its designed range.

Historical development of sleepers by material can be found for example in [4]. Sleepers made of wood are excellent for their shape adaptability, as well as flexibility adequate for track stiffness. However, their disadvantage is a short service life and tendency to biodegradability which leads to the necessity to be preserved using creosote oil which contains harmful substances [5]. In addition, the lack of quality hardwood for sleeper production is also a figure of importance. For these reasons, in the EU and in the world, the manufacture of wooden sleepers has been replaced with other materials, most often with prestressed concrete [6]. This durable type of sleeper has significantly expanded but the important disadvantage is its excessive bending stiffness which is much higher than of wooden sleeper. In addition, its weight and surface hardness leads to a small contact area between grains in ballast bed and the sleeper soffit [7]. It results in the considerable strain of grains, overloading, crushing, changing the grain size curve and consequently requiring maintenance. With 
regard to observed findings, it would be appropriate to apply material as durable as concrete along with flexibility observed at wooden and thus, the possible materials for the sleeper production could be recently applied polymers [8, 9]. The bending stiffness of a polymer sleeper is more in line with wooden sleepers or somewhat below. However, polymers have a viscoelastic behaviour, which creates a loading frequency dependent stiffness [10]. In order to compare the different types of sleeper materials, laboratory bending tests have been performed under different frequency loading.

\section{Methodology}

In a well maintained ballasted track, the sleeper should be supported by railway ballast mostly in the area of its rail seats. This is ensured by regular maintenance including tamping, ballast cleaning and refilling. However, tamping effects can deteriorate between maintenance actions. Considering cyclic load and accumulation of thousands of tons from passing trains, railway ballast can get worn and contaminated. Therefore, the ballast supporting function under the sleeper can deteriorate. As shown in Figure 1, in the case of prestressed concrete sleepers, this typically leads to voids under the sleeper ends and consequential bending. Within sleeper design characteristics, this is covered by the sleeper stiffness for negative bending moments. The stiffness can be determined in laboratory testing with the arrangement shown in Fig. 1. Contrary to a stiff prestressed concrete sleeper, the reduced ballast supporting function of wood or polymer sleepers is expected under the sleeper railseat. The aim of this research is the laboratory determination of the sleeper elastic modulus (E-modulus) in the sleeper negative bending test, in which the load and deflection are recorded.

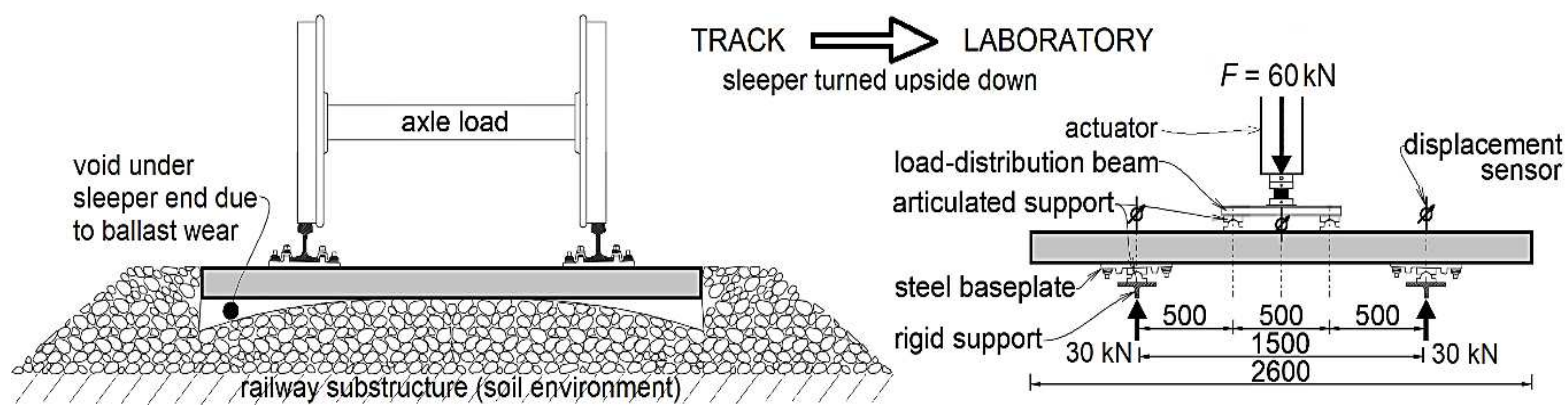

Fig. 1: Track with worn ballast maintenance resulting in deteriorated support under sleeper ends and consequential laboratory four-point bending test scheme for the negative bending moment.

\subsection{Description of sleeper samples}

The experiment was performed on sleeper material types typically used in a ballasted track construction including wood, polymer and prestressed concrete. Manufacturers of tested sleeper specimens are not specified in order to protect their intellectual property. Tested sleepers were of the rectangular cross-section with the exception of prestressed concrete sleeper with dimension alteration at its rail seats. The tested sleepers were new and did not show any visual damage before or after the testing. Before testing, sleepers were stored in the laboratory for 48 hours within the room temperature of $19^{\circ} \mathrm{C}$. The following two investigations of $E$-modulus in the laboratory bending test were conducted:

- Firstly, a set of 7 different sleeper types by material (Table 1) was tested in order to determine their $E$-modulus in changing loading frequency.

- Secondly, a set of impregnated beech sleepers (Table 2) was subjected to bending with a loading frequency of $5 \mathrm{~Hz}$ considering possible quality variability and its effect on $E$-modulus.

The first laboratory test included wooden sleepers represented by creosote oil impregnated beech and oak. The sleepers were impregnated with the creosote oil of type WEI-C with impregnation content up to $130 \mathrm{kgm}^{-3}$. In addition, a tropical wood of azobé was subjected to the test. Azobé is in itself resistant to wood-destroying insects and fungi and thus it was not chemically preserved. Dimensions of wooden sleepers were determined along the sleeper length, and because of their slight variation, the average width and height of sleepers were used in the evaluation.

Concerning sleepers on a polymer basis, one primary polymer sleeper and two recycled polymer sleepers were subjected to the experiment. The virgin one was made of polyurethane reinforced with fiberglass (in this article as referred to as PU). Furthermore, two types of sleepers made of recycled polyethylene reinforced with steel rebar were used. The specimen, referred to as 
high strength (HS) in this work, has a higher steel-to-plastic ratio. In contrast with HS, a sleeper referred to as PE has a lower steel-to-plastic ratio.

Finally, a prestressed concrete monoblock sleeper of B03 type was included as a reference due to its wide use. Considering different dimensions of the B03 sleeper in centre and rail seat section, the inertia moment is calculated on the base of weighted average dimensions.

Table 1: The characteristics of sleeper specimens by material subjected to bending experiment under changing frequency loading.

\begin{tabular}{|c|c|c|c|c|}
\hline Material & Sleeper type & Weight [kg] & Dimensions of cross section [mm] & Moment of inertia [mm $\left.{ }^{4}\right]$ \\
\hline \multirow{3}{*}{ Wood } & Oak & 102 & $259 \times 161$ & $9.0 \mathrm{E}+7$ \\
\cline { 2 - 5 } & Beech & 96 & $258 \times 160$ & $8.6 \mathrm{E}+7$ \\
\cline { 2 - 5 } & Azobé & 117 & $251 \times 151$ & $7.1 \mathrm{E}+7$ \\
\hline Polymer & PU & 100 & $226 \times 175$ & $10.1 \mathrm{E}+7$ \\
\hline \multirow{2}{*}{$\begin{array}{c}\text { Recycled } \\
\text { polymer }\end{array}$} & PE & 116 & $252 \times 152$ & $7.4 \mathrm{E}+7$ \\
\cline { 2 - 5 } & HS & 252 & $250 \times 151$ & $7.1 \mathrm{E}+7$ \\
\hline Concrete & Prestressed concrete & & $220 \times 190$ & $12.6 \mathrm{E}+7$ \\
\hline
\end{tabular}

In the second investigation, the bending experiment focused on eight impregnated beech sleepers. Since wooden products have their natural origin, the aim was to describe the possible piece by piece $E$-modulus variability of sleepers. Impregnated beech was chosen due to its availability for the experiment and due to the contemporary preference of beech over oak in the application of wooden sleepers in a track in the Czech Republic. The list of sleeper specimens is shown in Table 2.

Table 2: The characteristics of beech specimens subjected to bending experiment under cyclic load with frequency of $5 \mathrm{~Hz}$.

\begin{tabular}{|c|c|c|c|c|}
\hline Material & $\begin{array}{c}\text { Sequence number } \\
\text { in test }\end{array}$ & Weight [kg] & Dimensions of cross section [mm] & Moment of inertia [mm $\left.{ }^{4}\right]$ \\
\hline \multirow{4}{*}{$\begin{array}{c}\text { Impregnated } \\
\text { beech }\end{array}$} & 1 & 91 & $251 \times 156$ & $8.0 \mathrm{E}+7$ \\
\cline { 2 - 5 } & 2 & 93 & $257 \times 156$ & $8.1 \mathrm{E}+7$ \\
\cline { 2 - 5 } & 3 & 97 & $268 \times 155$ & $8.4 \mathrm{E}+7$ \\
\cline { 2 - 5 } & 4 & 94 & $262 \times 157$ & $8.4 \mathrm{E}+7$ \\
\cline { 2 - 5 } & 6 & 93 & $267 \times 151$ & $7.7 \mathrm{E}+7$ \\
\cline { 2 - 5 } & 7 & 92 & $260 \times 154$ & $7.9 \mathrm{E}+7$ \\
\hline
\end{tabular}

* The sleeper included also in the first part of the investigation.

\subsection{Loading sequence}

In the experiment, it was intended to subject sleepers to traffic-resembled loading usual for a conventional track as close to real traffic as reasonably practicable. Taking into account the sleeper on elastic Winkler foundation, an axle load, for instance, $180 \mathrm{kN}$, the wheel-load distribution via chosen rail profile, for instance, $49 \mathrm{E} 1$ over a number of sleepers due to its bending stiffness, the axle load redistributed to sleeper can be is around $35 \%$ [11]. The load $F$ of $60 \mathrm{kN}$ (Fig. 1) was adopted as an upper load value for the whole loading sequence presented below. The lower load was desired to be approaching zero, but the hydraulic cylinder requires certain seating force when alternating between lower and upper load. The minimal seating force depends on the specimen stiffness and consequent actuator travel and was determined as $20 \mathrm{kN}$.

The sleepers made of various materials shown in Table 1 have different rheological models. Especially the polymers exhibit a viscoelastic load response, reacting partly elastic and partly viscous. This means that the response to a load at a certain moment is not only related to the load at that moment, but also to the load history, resulting in a response that is different at different loading frequencies. For this reason, a test program was chosen which includes a quasistatic load that is changing in steps of frequency loading to dynamic load. The complete loading of a sleeper then consisted of 6 steps, each step with different loading frequency of $0.005,0.01,1,3,5$ and $7 \mathrm{~Hz}$ 
(Fig. 2). For the purpose of the comparability among loading frequency steps, every loading step lasted 15 minutes followed with 15 minutes time gap without load for creep deformation elimination. An overview of the two abovementioned tests performed and specimens is in Table 3.

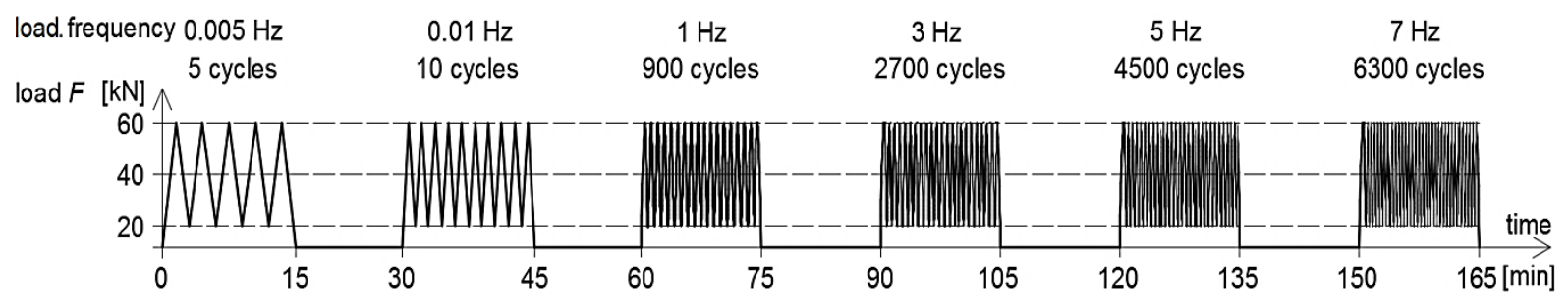

Fig. 2: Loading sequence for sleepers comprising the sequence of quasistatic and cyclic loading.

Table 3: Overview of tests performed.

\begin{tabular}{|c|c|c|c|}
\hline Material & Sleeper type & Loading frequency steps [Hz] & Number of specimens \\
\hline \multirow{4}{*}{ Wood } & Oak & $0.005-7$ & 1 \\
\cline { 2 - 4 } & Beech & 5 & 8 \\
\cline { 2 - 4 } & Beech & $0.005-7$ & 1 \\
\cline { 2 - 4 } & Azobé & $0.005-7$ & 1 \\
\hline \multirow{2}{*}{ Polymer } & PU & $0.005-5$ & 1 \\
\hline \multirow{2}{*}{ Recycled polymer } & PE & $0.005-5$ & 1 \\
\cline { 2 - 4 } & HS & $0.005-7$ & 1 \\
\hline Concrete & Prestressed concrete & $0.005-7$ & 1 \\
\hline
\end{tabular}

\subsection{Instrumentation of the laboratory experiment and sleepers' assembly}

The experiment (Fig. 3) was conducted using a loading frame supporting a hydraulic actuator Inova AHS 630-300 M01 with a maximal static load of $630 \mathrm{kN}$. The vertical displacement in the middle of the span $\left(D_{2}\right)$ and at the points above the rigid supports $\left(D_{1}\right.$ and $\left.D_{3}\right)$ were recorded using HBM WA/20mm type sensors with a range of $20 \mathrm{~mm}$ and an accuracy of $\pm 0.02 \mathrm{~mm}$. Data recording from sensors was performed by a Dewetron 30-16 logger. The sampling frequency for the $7 \mathrm{~Hz}$ cyclic loading was $100 \mathrm{~Hz}$.

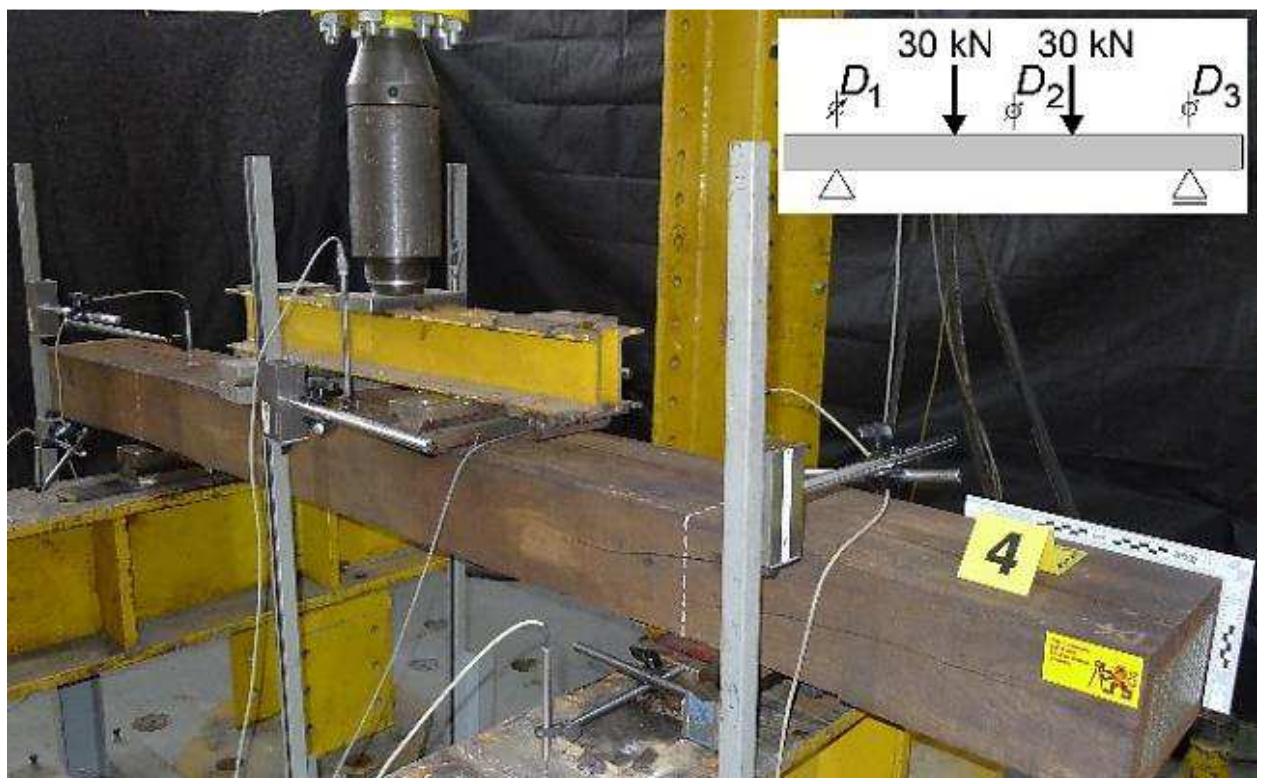

Fig. 3: Instrumentation of the laboratory four-point bending test.

Wood and polymer sleepers were assembled with an indirect fastening system that corresponds to their application on track. Ribbed baseplates of $\mathrm{RpH}$ type were installed on the sleeper surface at a distance corresponding to a standard track gauge. Baseplates were fixed by coach screws of Ss8 type 
with double helical spring washers of Fe 6 type. A rubber rail pad was placed on the base plate under the rail foot.

\section{Results and discussion}

This part describes the results of the experiment in which various sleepers by material were subjected to bending. During the experiment, the applied force and the corresponding vertical displacement of the sleeper were recorded. Following below-mentioned conditions, this enabled to calculate the $E$-modulus of sleepers. It can be calculated assuming linear elastic deformation of the beam in accordance with the Navier-Bernoulli hypothesis [12].

The elastic deformation was the objective of a previously conducted research which included strength analysis in bending on the same sleeper types. When testing sleepers, the force $F$ was increased in steps up to $200 \mathrm{kN}$ at which the test was terminated [13]. With the only exception of prestressed concrete, the sleepers did not achieve their elastic limit. Hereby, in this research, the traffic-like force $F$ of $60 \mathrm{kN}$ caused only elastic deformation of the sleeper. In Fig. 4 is the scheme, on the base of which the formula (1) is used for the $E$-modulus calculation.

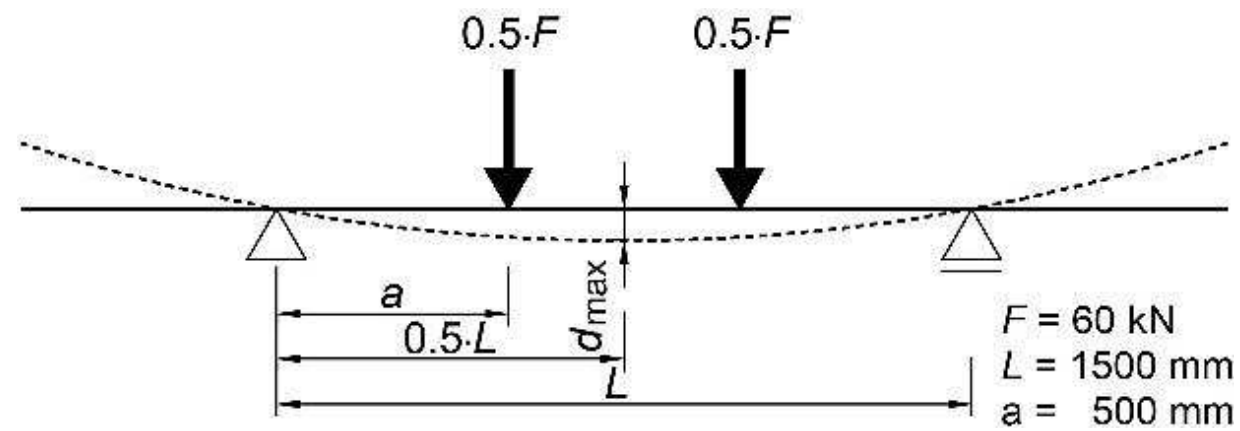

Fig. 4: Scheme for calculation of $E$-modulus from bending test data.

$E=\frac{F \cdot a\left(3 L^{2}-4 a^{2}\right)}{48 d_{\max } I}$

where $F$ represents the load on sleeper of $60 \mathrm{kN}$, a represents the distance between support and the point of load application, $L$ is the span, $d_{\max }$ is the deflection corresponding to $D_{2}$ decreased by support seating $\left(D_{1}\right.$ and $\left.D_{3}\right)$ and $/$ represents the moment of inertia in Table 1 and 2 . The value $d_{\max }$ did not occur at the same time as the force maximum, but slightly belatedly. However, in the forcedeflection graph, both maximums were found, paired and taken into calculations.

In formula (1) for calculating the E-modulus, data whilst increasing the applied force were taken into account. The E-modulus for sleepers listed in Table 1, which were subjected to changing loading frequency, is presented individually in Fig. 5 and summarized in Fig. 6. As noticed for the oak sleeper in Fig. 5 , the E-modulus was evaluated from each quasistatic load $(0.005$ and $0.01 \mathrm{~Hz})$. However, in cyclic loading significantly more cycles were performed than in quasi-static loading. Thus, the average $E$-modulus, which corresponds to the last ten loading cycles, was evaluated. Since the $E$-modulus of the wooden and polymer sleepers is fundamentally different from prestressed concrete, the scale of a vertical axis follows the division of material. This form was chosen because columns then indicate more clearly the behaviour of sleepers for different loading frequency, i.e. their $E$-modulus increase. 


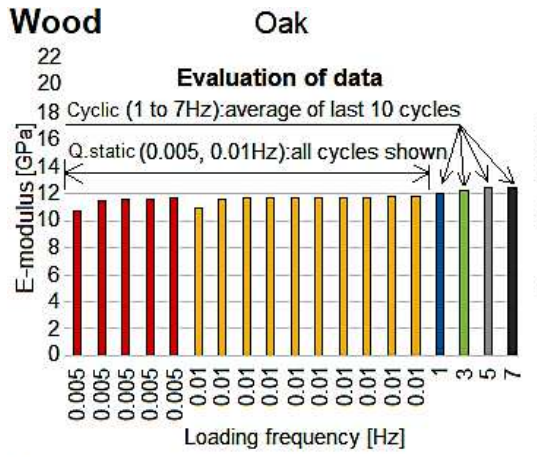

Polymer PU

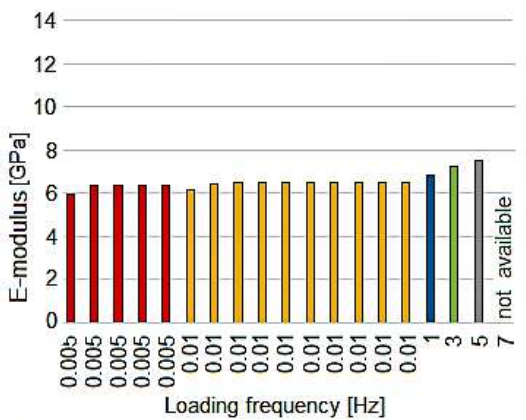

Prestressed concrete

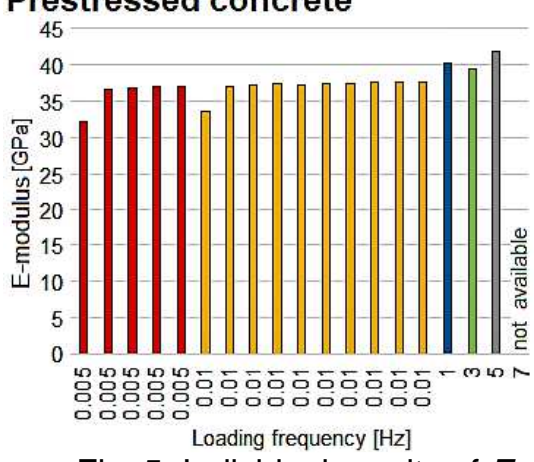

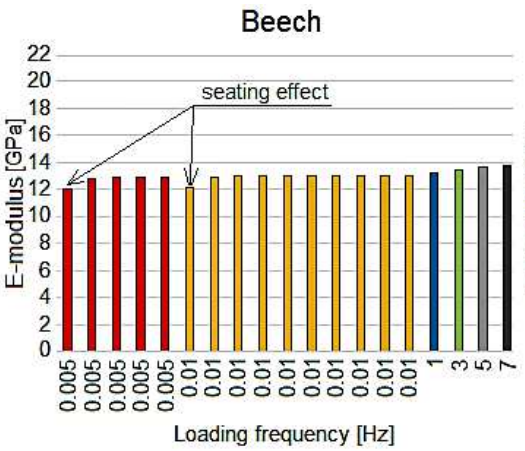

PE

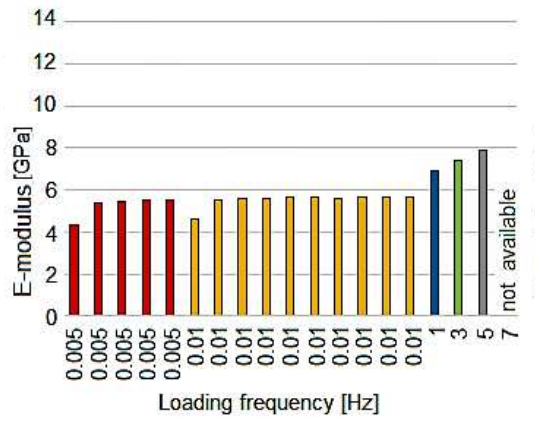

Loading frequency $[\mathrm{Hz}]$

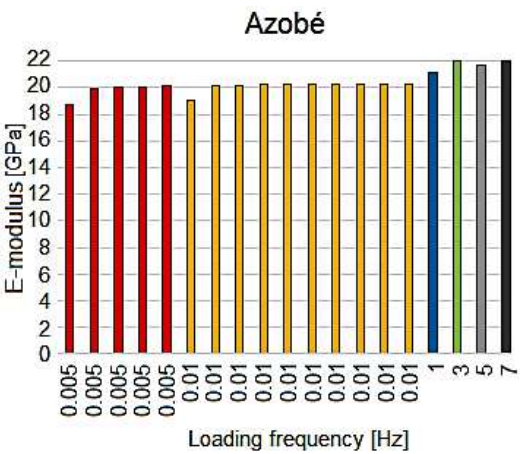

HS

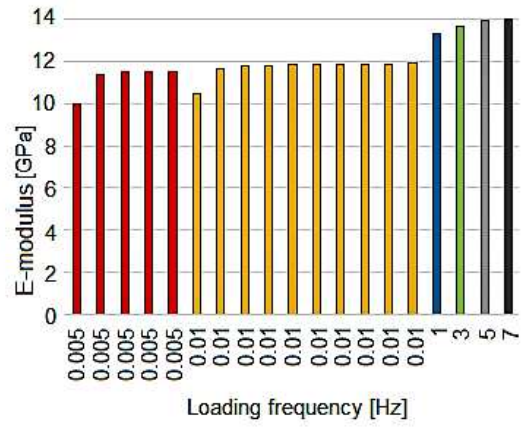

Fig. 5: Individual results of $E$-modulus for different sleeper materials and loading frequencies.

The steps in loading frequency were intermitted with 15 minutes pauses with zero loads. Thus, there was no preload when beginning further loading frequency step. Therefore, the lower value of $E$ modulus in every first quasistatic loading step is caused by seating effects as shown for the beech sleeper in Fig. 5, [14].

It was found out, that sleepers even after accumulating 6,000 of loading cycles behave elastically. The sleepers under quasistatic load resembled the effect of static force, which does not cause the influence of inertia and damping forces and thus the change of the E-module did not occur. The results showed that oak and beech sleepers have comparable E-modulus, whilst Azobé double.

A similar experiment aiming to the determination of the $E$-modulus of wooden sleepers in order to obtain the design value for polymer sleepers was performed by Ticoalu et al. [15] The subject matter was wooden railway sleepers of an unspecified type with a test beam span of $2.7 \mathrm{~m}$ and a static force load increased to failure. The average E-modulus was $14.9 \mathrm{GPa}$. The difference with hereby presented values can be in types and origin of wood tested by Ticoalu.

Fig. 6 summarizes the E-modulus of sleepers by material and changing loading frequency where 0.005 and $0.01 \mathrm{~Hz}$ are represented always with the last quasistatic loading step. The main feature of this graph is the same scale on vertical axis enabling the comparability of $E$-modulus between materials. 


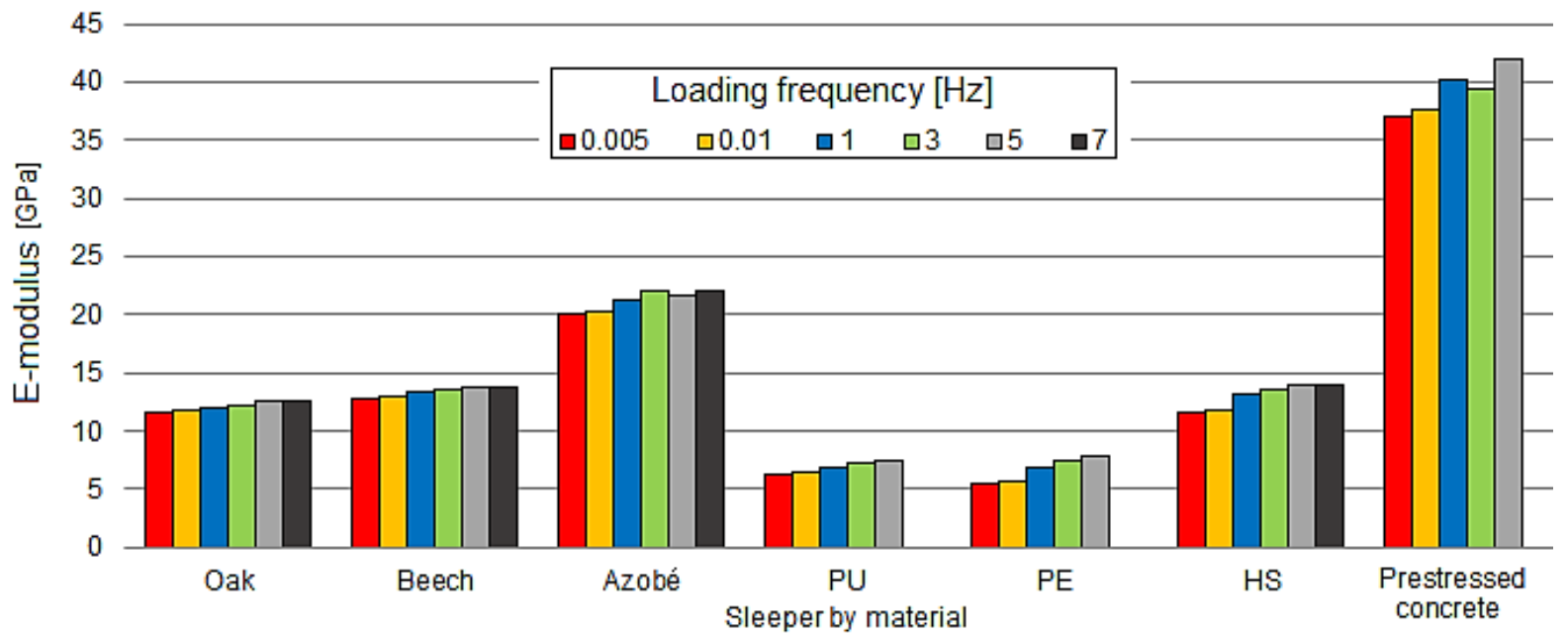

Fig. 6: Summary of $E$-modulus for different sleepers by materials and loading frequencies.

When comparing quasistatic loading results at 0.005 and 0.01 , the sleepers have a comparable $E$-modulus. However, at frequencies of $1 \mathrm{~Hz}$ or higher, the increase in $E$-modulus was noticeable. For this reason, it was advisable to focus on $E$-module increments depending on the increase in load frequency, which is calculated in Table 3.

Table 3: Increase in E-modulus relatively to quasistatic loading of $0.005 \mathrm{~Hz}$ for different sleeper materials due to increased loading frequency.

\begin{tabular}{|c|c|c|c|c|c|c|}
\hline \multicolumn{7}{|c|}{ Increase in E-modulus in [GPa] and [\%] } \\
\hline Loading frequency [Hz] & 0.005 & 0.01 & 1 & 3 & 5 & 7 \\
\hline Oak & 11.7 & $+0.1(+\mathbf{1} \%)$ & $+0.4(+\mathbf{3} \%)$ & $+0.5(+5 \%)$ & $+0.8(+\mathbf{7} \%)$ & $+0.8(+\mathbf{7} \%)$ \\
\hline Beech & 12.9 & $+0.1(+\mathbf{1} \%)$ & $+0.4(+\mathbf{3} \%)$ & $+0.7(+\mathbf{5} \%)$ & $+0.9(+\mathbf{7} \%)$ & $+1.0(+\mathbf{7} \%)$ \\
\hline Azobé & 20.1 & $+0.1(+\mathbf{1} \%)$ & $+1.1(+5 \%)$ & $+1.9(+\mathbf{9} \%)$ & $+1.6(+\mathbf{8} \%)$ & $+1.9(+\mathbf{9} \%)$ \\
\hline PU & 6.4 & $+0.1(+\mathbf{2} \%)$ & $+0.5(+\mathbf{8} \%)$ & $+0.9(+\mathbf{1 4} \%)$ & $+1.2(+\mathbf{1 8} \%)$ & $\mathrm{N} / \mathrm{a}^{*}$ \\
\hline PE & 5.5 & $+0.1(+\mathbf{3} \%)$ & $+1.4(+\mathbf{2 5} \%)$ & $+1.9(+\mathbf{3 4} \%)$ & $+2.4(+\mathbf{4 3} \%)$ & $\mathrm{N} / \mathrm{a}^{*}$ \\
\hline HS & 11.5 & $+0.4(+\mathbf{3} \%)$ & $+1.7(+\mathbf{1 5} \%)$ & $+2.1(+\mathbf{1 9} \%)$ & $+2.4(+\mathbf{2 1} \%)$ & $+2.5(+\mathbf{+ 2 1} \%)$ \\
\hline Prestressed concrete & 37.1 & $+0.5(+\mathbf{1} \%)$ & $+3.1(+\mathbf{8} \%)$ & $+2.3(+\mathbf{6} \%)$ & $+4.8(+\mathbf{1 3} \%)$ & $\mathrm{N} / \mathrm{a}$ * \\
\hline
\end{tabular}

* Technical limit of laboratory equipment: loading frequency of $7 \mathrm{~Hz}$ not available due to considerable travel of the actuator consuming excessive hydraulic system pressure.

Beech, oak, azobé and prestressed concrete sleeper have different stiffnesses, but the cyclic loading and increasing the load frequency from 0.005 to $7 \mathrm{~Hz}$ have only a marginal effect on the E-modulus. The effect of inertia and damping forces is below $10 \%$ and there is no large increase in $E$-modulus. However, increasing $E$-modulus by tens of percent is evident in sleepers made of polymers. It is concluded that the increase in E-modulus when increasing the load frequency is due to the viscoelastic behaviour of the polymers.

The E-modulus for beech sleepers in Table 2 subjected to a cyclic load of $5 \mathrm{~Hz}$ is shown in Fig. 7. The E-modulus spread was between 8.5 and $13.8 \mathrm{GPa}$ with the average value and standard deviation of $(10.9 \pm 1.5) \mathrm{GPa}$. In comparison to mean $E$-modulus and standard deviation of (16.6 \pm 6.2$) \mathrm{GPa}$ determined by Ticoalu in [13], the hereby presented variation of $E$-modulus can be considered relatively low. 


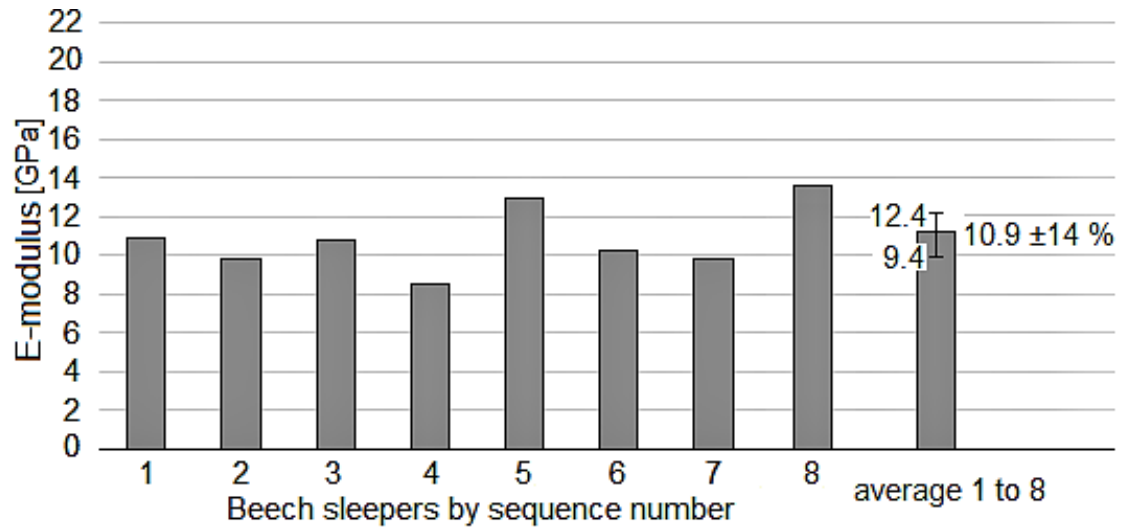

Fig. 7: Individual results of $E$-modulus for beech sleepers and loading frequency of $5 \mathrm{~Hz}$.

\section{Conclusion}

Railway sleepers applied in ballasted track play a role in track stiffness. While prestressed concrete sleepers are often preferred for their durability with sufficient applicable properties, the more elastic sleeper can be advantageous or even desired for tracks where it is advisable to use flexible rail supports. This research investigated the sleeper mechanical resistance represented by E-modulus and especially its dependency on changing loading frequency. The test was conducted on various sleepers reflecting the contemporary materials used in the sleeper production.

$E$-modulus of wood showed comparable $E$-modulus at loading frequency 0.005 to $7 \mathrm{~Hz}$. $E$-modulus of polymer sleepers is comparable to beech and oak sleepers or lower depending on sleeper type, hence from the perspective of sleeper elasticity, the tested polymer sleepers can be an appropriate alternative when replacing wooden sleepers.

When loading polymer sleepers, viscous-elastic behaviour was identified as the frequency dependent stiffness when loading with frequency $1 \mathrm{~Hz}$ and higher resulting in increasing $E$-modulus, whilst wooden sleepers indicate mainly elastic behaviour.

Since $E$-modulus of polymer sleepers increases significantly with loading frequencies, a standardized laboratory testing of polymer sleepers should be performed with a dynamic frequency of $5 \mathrm{~Hz}$ or higher reflecting the trainload frequency given with permissible speed in railway track.

In the second part, test performed on the set of 8 impregnated beech sleepers, the results confirmed the assumption that mechanical properties of sleepers presented by $E$-modulus can vary due to the natural origin of the wood.

\section{Acknowledgements}

This work was partially supported by the Grant Agency of the Czech Technical University in Prague, grant No. SGS $161-1611850137$.

\section{References}

[1] BONNETT, C.: Practical railway engineering. London: Imperial College Press, 1996.

[2] ESVELD, C.: Modern railway track, Second. MRT-Productions, 2001.

[3] BELKOM, A.: Recycled Plastic Railway Sleepers: Analysis and Comparison of Sleeper Parameters and the Influence on Track Stiffness and Performance. Railway Engineering 2015, p. 20.

[4] LOJDA, V.: The historical development of railway sleepers from the perspective of material: from stone to polymers. RDT 2nd Research, Development and Innovation in Transport - RDIT 2018 Ostrava, ISBN 978-80-248-4270-7.

[5] THIERFELDER, T. - SANDSTRÖM, E.: The creosote content of used railway crossties as compared with European stipulations for hazardous waste. Science of the Total Environment, Vol. 402 (1), 2008, pp. 106-112, doi: 10.1016/j.scitotenv.2008.04.035.

[6] SUWOS: Sustainable wooden railways sleepers. Paris: International Union of Railways. Available at: www.uic.org/download.php/publication/538E.pdf (2013). 
[7] LOJDA, V. - JEŘÁBEK, J. - HORNÍČEK, L.: Utilizing a pressure paper for the determination of contact parameters between aggregate and a railway sleeper. 19th International multidisciplinary Scientific GeoConference SGEM 2019, pp. 565-572, doi: 10.5593/sgem2019/1.2/S02.072.

[8] MANALO, A. et al.: A review of alternative materials for replacing existing timber sleepers. Compos. Struct., Vol. 92, No. 3, 2010, pp. 603-611.

[9] LOJDA, V. - BELKOM, A.: Fire safety of polymer sleepers in terms of fire propagation. 19th International Multidisciplinary Scientific GeoConference SGEM 2019, pp. 247-256, doi: 10.5593/sgem2019/1.2/S02.032

[10] EHRENSTEIN, G. W.: Polymer composite materials. Prague, 2009.

[11] SHOKRIEH, M. - RAHMAT, M.: Effects of Young's modulus on response of railway sleeper. Appl.Math. Model., Vol. 31, No. 4, 2007, pp. 700-711.

[12] MINDLIN, R. D.: Influence of rotatory inertia and shear in flexural motions of isotropic elastic plates. Journal of Applied Mechanics, Vol. 18, 1951, pp. 31-38.

[13] LOJDA, V.: Strength analysis investigation of sleeper types by material. 2019.

[14] SUSSMAN, T. R. - EBERSOHN, W. - SELIG, E. T.: Fundamental Nonlinear Track Load Deflection Behaviour for Condition Evaluation. Transportation Research Record, Vol. 1742 (1), 2001, pp. 61-67.

[15] TICOALU, A. - ARAVINTHAN, T. - KARUNASENA. W.: An investigation on the stiffness of timber sleepers for the design of fibre composite sleepers. Available at: https://eprints.usq.edu.au/4849/1/Ticoalu_Aravinthan_Karunasena_ACMSM20_AV.pdf. 